\title{
Participação Popular E Poder Judiciário: Uma Possibilidade Para A Proteção Ambiental
}

\section{Alexandre Abel Mariotti}

Mestrando em Direito Ambiental pela Universidade de Caxias do Sul (UCS)

\section{Bruna Souza Fernandes}

Mestranda em Direito Ambiental pela Universidade de Caxias do Sul (UCS)

\section{Carlos Alberto Lunelli}

Doutor e Mestre pela Universidade do Vale do Rio dos Sinos. Professor titular da Universidade de Caxias do Sul, no Mestrado em Direito.

Resumo: A participação popular, forma direta de concretização da soberania popular, é hoje uma realidade que se estrutura no Estado Socioambiental. No entanto, para a materialização de uma democracia participativa e efetivamente ativa nas questões ambientais é indispensável uma atuação consciente e informada da sociedade sobre os mecanismos processuais que são disponibilizados. Em contrapartida é fundamental a politização do Poder Judiciário no trato com a matéria ambiental, devendo assumir uma postura mais ativa. Assim, o artigo discorre sobre a imprescindível relação entre uma democracia participativa que busca preservar o meio ambiente e um Poder Judiciário que se espera dinâmico, criativo e garantidor do direito ao meio ambiente ecologicamente equilibrado, bem de uso comum do povo e essencial à sadia qualidade de vida. Para a pesquisa foi utilizado o método hermenêutico, utilizando-se a técnica de pesquisa bibliográfica, método que se revela adequado à ciência jurídica e que permite a compreensão acerca da importância da efetividade da tutela processual ambiental.

Palavras-chave: Democracia participativa. Participação Popular. Acesso à Justiça. Poder Judiciário.

\section{UNIVERSIDADE FEDERAL DA PARAÍBA}




\title{
Participação Popular E Poder Judiciário: Uma Possibilidade Para A Proteção Ambiental
}

\author{
Alexandre Abel Mariotti \\ Bruna Souza Fernandes \\ Carlos Alberto Lunelli
}

1 INTRODUÇÃO

É comum a afirmação de que a democracia é o governo estruturado para atender aos interesses do povo. Partindo dessa noção o debate que se apresenta tem por objeto a possibilidade da efetiva participação popular, por meio de uma atuação judicial, na implementação do disposto no caput artigo 225 da Constituição Federal.

Inicialmente, há que se ter presente que democracia, cidadania e dignidade humana estão intimamente ligadas, nos termos do artigo $1^{\mathrm{O}}$ e incisos, da Constituição da República Federativa do Brasil de 1988. Assim, a participação popular por meio do acesso ao Poder Judiciário implica busca da efetivação da democracia.

É inegável o papel constitucional do Poder Judiciário, até então considerado um poder onde a função do juiz compreende-se limitada a aplicar a lei, quando incitado a atuar. Neste ponto, uma questão importante que se apresenta, no tocante à proteção ambiental, é o reclamo de atuação do Judiciário para implementação 
Participação Popular E Poder Judiciário: Uma Possibilidade...

das normas estabelecidas e não cumpridas pelos Poderes Legislativo e Executivo.

Assim, espera-se que o Poder Judiciário atue ativamente na produção e efetivação de medidas ambientais concretas, papel compreendido como restrito aos outros dois poderes e, exercendo função que vai além daquela preconizada na tradicional divisão do Estado Democrático de Direito.

Muito embora as críticas acerca de uma atuação desmedida do Poder Judiciário sejam comuns, é fato que ele assume papel relevante na contemporaneidade, justificando-se o clamor por uma soberania popular, que propicie a efetivação das garantias de proteção ambiental.

São diversos os instrumentos processuais colocados à disposição da sociedade para garantir a proteção ambiental. Entre outros exemplos, pode-se citar a ação civil pública que, além de outros objetivos, tenciona a tutela do meio ambiente e a fiscalização das políticas públicas pelos entes políticos, a ação popular e as ações direta de inconstitucionalidade e declaratória de constitucionalidade.

Desta forma, pretende-se trazer contribuições em relação ao papel da democrática participação popular por intermédio de um Poder Judiciário dinâmico, criativo e garantidor do bem ambiental.

\section{DEMOCRACIA E SEPARAÇÃO DOS PODERES NO ESTADO CONTEMPORÂNEO}

O princípio da separação dos poderes representou uma garantia ao cidadão, afirmando a liberdade individual. Representou o modo de superação do absolutismo, a partir das teorias de Locke, 
Montesquieu e Rousseau. Divisão dos poderes no Estado contradiz a própria essência do governo absoluto, caracterizado pela existência de um único titular que exerce todos os poderes. Assim, a cisão do poder foi a forma encontrada para que o absolutismo, típica forma de concentração do poder, desse lugar a um novo modo de compreensão do estado.

De acordo com Signorino, "nella storia politica rappresenta l’affermazione pratica dei diritti politici dei cittadini, chè la divisione dei poteri fu intesa nel senso di attribuire una parte del potere supremo dello Stato alla nazione, per mezzo dei suoi rappresentanti” (tradução livre dos autores: "na história política representa a afirmação prática dos direitos dos cidadãos, que a divisão dos poderes compreendeu no sentido de atribuir uma parte do poder supremo do Estado à nação, por meio de seus representantes”) (SIGNORINO, 1908, p. 140). A divisão dos poderes representou a ponte que permitiu a passagem do estado absoluto para o estado constitucional.

Conquanto exista a discussão acerca do reconhecimento, ainda em Aristóteles, de uma separação dos poderes do Estado, Aristóteles não criou nenhuma teoria, mas limitou-se a descrever as linhas principais do que havia então nas cidades gregas.

Locke distinguiu somente dois poderes, executivo e legislativo. Foi com Montesquieu que se estabeleceu a clássica tripartição, trazendo o Poder Judiciário, ao qual foi atribuída também a função de controle da administração. Como refere Bognetti,

[...] la sottoposizione dell `amministrazione al controllo della giustizia è un `esigenza imprescindibile - come è agevole intuire - di un modello costruito in funzione dei diritti delle persone. Come tale non poteva non trovare soddisfazione, almeno in qualche misura, presso tutti gli ordinamenti liberali" (tradução livre dos autores: "a submissão da administração ao controle judicial é uma exigência indispensável - como é fácil perceber - de um modelo construído em função dos direitos das pessoas. Como tal, não 
poderia deixar de encontrar satisfação, ao menos em alguma medida, junto a todos os ordenamentos liberais") (BOGNETTI, 1994, p. 40).

A própria conceituação de poder permite algumas discussões interessantes. George Burdeau reconhece que o governante mesmo não pode definir o próprio poder, porque ao governante cabe apenas externar um poder que está além dele mesmo. Assim, diz Burdeau que "En effet, le Pouvoir ne peut pas être défini par les gouvernants, puisque, dans le régime étatique, ils ne font que mettre em oeuvre une puissance qui les dépasse." (tradução livre dos autores: “De fato, o Poder não pode ser definido pelos governantes, uma vez que, no regime estatal, eles apenas implementam um poder que os sustenta") (BURDEAU, 1950, p. 102)

Além disso, ao discorrer sobre o poder, é preciso perceber de que poder se trata. O exercício do poder, a administração pública contemporânea, haverá de realizar-se em consonância com o estado democrático de direito e com os valores afirmados na sociedade contemporânea. Não se trata apenas do exercício do poder. É preciso mais, especialmente que esse poder seja exercido a fim de que se realize e se garanta a observância do ordenamento jurídico.

É por isso que a substância das ordens emanadas, a partir do exercício do poder, tem importância reconhecida por Georges Burdeau, que adverte: "Dire par qui et comment sera exercé le Pouvoir c`est bien, mais encore faut-il savoir de quel Pouvoir il s`agit. Déterminer dans quelles conditions les décisions et les commandements devront être tenus pour réguliers c`est nécessaire sans doute à l'ordre public, mais il importe au moins autant de déterminer quelle pourra être la substance des ordres". (tradução livre dos autores: "Dizer porque o como será exercido o poder é fácil, mas ainda é preciso saber de que poder se trata. Determinar em quais condições as decisões e as ordens devem ser compreendidas como regulares é, sem dúvida, necessário à ordem pública, mas também é 
importante para determinar a substância dessas ordens"). (BURDEAU, 1950, p. 102)

Enfim, afora esses elementos, a clássica discussão acerca da própria divisão dos poderes perdeu sua expressão, na medida em que a consolidação do estado democrático de direito permitiu a compreensão de que a divisão de que se cuida e, enfim, uma divisão de funções.

Com efeito, há mais de cinquenta anos, Loewenstein já afirmava que a "separação dos poderes" representa um conceito obsoleto, porque reduzido a simples separação de funções entre os diferentes órgãos: "What is colloquially, in erroneously, spoken of as the separation of powers is operationally only the distribution of specific state functions among different state organs" (tradução livre dos autores: "O que é de modo coloquial, equivocadamente, dito como separação de poderes é operacionalmente apenas a distribuição de funções específicas do estado entre os diferentes órgãos estatais). (LOEWENSTEIN, 1965, p. 36). O poder está repartido, por sua vez, através das técnicas de representação, nas democracias representativas.

A questão, então, passa pela própria repartição de funções, dentro do estado. No caso brasileiro, a ausência de atuação efetiva do poder executivo, no tocante à saúde, conduz ao deslocamento da questão ao Poder Judiciário, numa evidente transferência de funções. Essa transferência não é um privilégio do Brasil, porque ocorre também em inúmeros outros países. Porém, no caso brasileiro, a ausência de políticas públicas eficazes - que, inclusive, permitam a análise do caso individual - torna ainda mais expressiva essa judicialização.

A possível assunção, pelo Poder Judiciário, da função que deveria ser realizada pelo poder executivo, pode representar uma anomalia, na medida em que um dos poderes constituídos não está realizando sua função, exigindo-se do outro essa consecução. Todavia, ao Poder Judiciário cabe também a fiscalização dos atos do 
executivo e a complexidade das relações e das demandas envolvendo a proteção ambiental, reclama atuação célere, já que se trata de proteger e garantir a continuidade da vida.

Ao final se trata, como diz Burdeau, do próprio exercício do poder estatal, pelos governantes, que terminam por concretizar o próprio poder. Se o ordenamento constitucional garante o direito ao bem ambiental, então o comando que opera no sentido de realizar esse direito, ainda que oriundo de outro poder, que não o executivo, não ofende nem mesmo ao princípio da divisão dos poderes, ainda que considerado em seu sentido mais original. O Poder Judiciário é um dos órgãos do estado, esse mesmo estado que tem a obrigação de proteger o ambiente:

\footnotetext{
Parce qu `ils sont les organes de l`Etat, les gouvernants prêtent une figure concrête au Pouvoir, ils lui apportent ce qui lui fait défaut à titre de pouvoir étatique, c`est-àdire une volonté; ils mettent en action, pour lui, la force contraignante que accompagne les prérrogatives de puissances publique. (tradução livre dos autores: "Porque eles são os órgãos do Estado, os governantes conferem uma figura concreta ao Poder, agregando o que ele não tem como poder estatal, isto é, uma vontade; eles colocam em ação, para ele, a força obrigatória que acompanha as prerrogativas dos poderes públicos"). (BURDEAU, 1950, p. 157)
}

A afirmação de que é possível - e devido - o controle dos atos da administração pública, pelo judiciário, também implica na admissibilidade da atuação do Poder Judiciário no momento em que o poder executivo não realiza as diretrizes estabelecidas no ordenamento constitucional.

Trata-se também de garantir a realização de um dos papéis do Poder Judiciário, que é também o de produtor do próprio direito, a partir da atividade de aplicação da previsão legislativa ao caso concreto. Essa aplicação, todavia, haverá de realizar-se a partir da 
análise de todosos elementos que se fazem presentes na atividade jurisdicional, bem percebidos por Zanon, quando afirma "Il giudice non si limita ad applicare meccanicamente la decisione politica assunta in via generale dal legislatore, bensì attribuisce alla legge uno dei significati possibili (e lessicalmente tollerabili), e da questo punto di vista la sua è una vera decisione, spesso orientata da una precomprensione del singolo caso, alla luce di valori soggettivi" (tradução livre dos autores: "O juiz não se limita a aplicar mecanicamente a decisão política assumida generalizadamente pelo legislador, mas atribui à lei um dos significados possíveis (e lexicalmente toleráveis) e desse ponto de vista a sua é uma verdadeira decisão, orientada por uma pré-compreensão do caso singular, à luz dos valores subjetivos") (ZANON, 2008, p. 227). Enfim, a aceitação de que o Poder Judiciário possa exercer a função de garantir a realização do direito ao ambiente equilibrado, ainda que sem a primária intervenção do administrador público, não implica violação à separação dos poderes, podendo ser compreendida, em vez disso, como uma nova forma de repartição de funções dentro do mesmo poder.

Assim, pode-se afirmar que a representação de um "Estado Constitucional (ou de Direito)" se assenta sobre a concepção de um Estado ligado pela ideia de uniformidade entre todos os integrantes (CLÉVE, 2000, p. 30). Importa observar que, para Canotilho (1993, p. 31) "[...] o Estado constitucional só é constitucional se for democrático".

E aqui vale também considerar que a democracia deve ser entendida não somente como a forma de constituição de um governo, mas "[...] uma espécie de sociedade em que o desenvolvimento da pessoa humana é a finalidade, e a cooperação é o método.” (HUSZAR, 1965, p. 18)

Logo, esse Estado deve, além de garantir os direitos e liberdades dos cidadãos, encontrar uma maneira de concretizar essas balizas que compõe o Estado Democrático de Direito, cujo objetivo é 
Participação Popular E Poder Judiciário: Uma Possibilidade...

a "realização da democracia económica, social e cultural e o aprofundamento da democracia participativa" (CANOTILHO, 1993, p. 64).

Afirma-se, assim, que o Estado Democrático de Direito, visto como princípio, representa um "[...] superconceito, do qual se extraem - por derivação, inferência ou implicação - diversos princípios, como o da separação dos Poderes, o do Pluralismo político, o da isonomia, o da legalidade e, até mesmo, o princípio da dignidade humana [...]” (MENDES; COELHO; BRANCO, 2010, p. 213).

Igualmente, é preciso considerar que o Estado Democrático de Direito contém - além das diretrizes de realização de uma democracia participativa e voltada para as questões econômicas, sociais e culturais - diversos princípios que fundamentam sua formação: (i) princípio da constitucionalidade; (ii) princípio democrático; (iii) sistema de direitos fundamentais; (iv) princípio da justiça social; (v) princípio da igualdade; (vi) princípios da divisão de poderes e da independência do juiz; (vii) princípio da legalidade e (viii) princípio da segurança jurídica (SILVA, 2013, p. 124).

A Constituição - muito embora as críticas hoje apontadas sobre a sua extensão e análise esmiuçada de normas - originou-se da vontade popular, ainda que produto de uma negociação entre militares e líderes políticos (Ferreira Filho, 1995, p. 20) e não fundada numa revolução. É vista, pois, como diploma destinado a atender aos anseios e direitos do povo, facultando mecanismos para sua efetivação.

Consagradora de uma democracia representativa e participativa, a Constituição avança para uma democracia moderna, que, por certo, não se iguala à democracia antiga - onde os cidadãos deliberavam diretamente sobre as questões políticas -, tendo em vista o elevado número de cidadãos no estágio presente do estágio democrático. Embora o poder seja do povo e para o povo é exercido por intermédio dos representantes eleitos, que devem prestá-lo no 
intuito do bem comum. No entanto, esse desiderato nem sempre é observado, uma vez que se percebe a atuação política em favor de pequenos grupos e elites.

Não há como negar que o reconhecimento de uma "classe política significa necessariamente reconhecer que ela tem interesses próprios, diferentes, portanto, dos interesses do povo e dos demais grupos sociais" (FERREIRA FILHO, 2003, p. 38).

Contudo, não pode ser olvidada outra faceta dessa nova democracia: a participativa, criadora de "mecanismos de exercício direto da vontade geral e democrática suscetíveis de restaurar e repolitizar a legitimidade do sistema" (BONAVIDES, 2003, p. 22).

A aceitação de que a democracia participativa é uma das possibilidades, inclusive permitindo a participação do Poder Judiciário, no exercício pleno da função jurisdicional, constitui uma das possibilidades de garantir-se a efetivação do Estado Democrático de Direito e, especialmente, a efetividade da proteção ambiental.

\section{JURISDIÇÃO, IDEOLOGIA E TUTELA DO BEM AMBIENTAL.}

A tutela jurisdicional precisa desempenhar seu objetivo primário, garantindo ao titular do direito aquilo que está afirmado no direito material. $\mathrm{O}$ atingimento desse objetivo depende de muitos fatores e a função jurisdicional, nesse talante, "bisogna articolarsi in modo estremamente vario e complesso" "“é necessário articular-se de modo extremamente variado e complexo). (PROTO PISANI, 2008, p. 32) 
Participação Popular E Poder Judiciário: Uma Possibilidade...

A construção de que ao Judiciário cabe unicamente o papel de reproduzir a lei também expressa o compromisso ideológico, tornando o juiz refém do texto legal, como se fosse possível reduzir essa atividade a tal desiderato. Nesse sentido, Ovídio Baptista da Silva afirma que "os dois principais compromissos ideológicos inerentes à nossa compreensão do Direito e da missão do Poder Judiciário revelam-se claramente: a ideia que o juiz somente deve "respeito à Lei", sendo-lhe vedado decidir as causas segundo sua posição política" (BAPTISTA DA SILVA, 2004, p. 21). Essa proposição de Ovídio Baptista da Silva representa não mais do que a recuperação de institutos do próprio Direito Romano. Mário Bretone assinala que "La piú antica giurisprudenza vuole, da un lato, non discostarsi della lettera della legge, dall 'altro esercitare la propria libertà inventiva e creativa." (tradução livre dos autores: "a mais antiga jurisprudência quer, de um lado, não afastar-se da letra da lei e, de outro, exercitar a própria liberdade inventiva e criativa"). (BRETONE, 1982, p. 307). Trata-se, enfim, de trazer de volta o que foi perdido no mundo contemporâneo, a partir do pensamento racionalista.

Enfim, também quando se pensa na tutela do ambiente, não se revela suficiente a proteção legal, é preciso ainda que o administrador atue no sentido de realizar essa proteção. Em casos como o que se apresenta, em que termina ocorrendo a transferência da realização da proteção ambiental ao Judiciário, é ainda necessário que o juiz esteja disposto a acolher a pretensão do autor. A simples edição da legislação, garantindo a proteção da saúde, por si não é suficiente a assegurar a efetividade da tutela. Está aí, a demonstrar tal aspecto, a própria tutela no caso brasileiro. Essa questão que envolve a legislação ambiental tem, evidentemente, uma expressão determinada pelo avanço da legislação ambiental, no momento atual. É claro que a legislação ambiental é essencial para a proteção do ambiente, mas na caminhada já trilhada, pode-se perceber que a afirmação da garantia ao ambiente equilibrado já se deu nos 
ordenamentos legais. O que é preciso, agora, é garantir efetividade a essa afirmação.

A atividade do julgador é inegavelmente ideológica. E, de acordo com o pensamento de Warat (1996, p. 69), que afirma “[...] a ideologia pode ser também considerada como uma dimensão pragmática da linguagem. A ideologia não só se encontra presente no discurso natural, como também constitui um sistema de evocações contextuais surgidas no uso pragmático do discurso científico" é fácil perceber que a atividade jurisdicional é indissociável desse elemento.

É que a ideologia, dimensão que se agrega ao processo, precisa ser compreendida em conjunto com a própria técnica processual, porque é a ideologia que determina os próprios rumos que se dará ao processo, questão que é bem percebida por Taruffo, quando afirma que "In sostanza, il processo non è pura tecnica e la sua conoscenza non si esaurisce nella cultura tecnica. La tecnica serve a fabbricare lo strumento processuale, mentre l'ideologia determina gli scopi che il processo dovrebbe conseguire" (tradução livre dos autores: "Em essência, o processo não é pura técnica e a sua compreensão não se exaure na cultura técnica. A técnica serve para produzir o instrumento processual, enquanto que a ideologia determina os objetivos que o processo deve alcançar") (TARUFFO, 2009, p. 68). Não é possível ao operador do processo limitar-se à técnica, porque essa limitação produz uma visão míope, incapaz de perceber as diferentes dimensões que produzem influência na produção processual.

No âmbito da proteção ambiental, na esteira do pensamento de Aquilina e Iaquinta (2013, p. 48), é preciso que se possa transformar a ameaça que se põe à humanidade, de sua própria extinção, no impulso necessário para encontrar alternativas que permitam a continuidade da vida, não apenas de sobrevivência, mas de vida digna e em condições que possam ser alcançadas também às futuras gerações. 
Participação Popular E Poder Judiciário: Uma Possibilidade...

O direito ao ambiente equilibrado, compreendido como expressão da sadia qualidade de vida, ainda está longe de ser uma realidade na sociedade brasileira, inobstante tenha merecido ampla tutela no ordenamento jurídico e elevado ao status de direito fundamental, com sua inserção na Constituição Federal de 1988.

Dificuldades estruturais do país, inclusive falta de recursos orçamentários, aliadas à tendência de tratar o tema da saúde como questão privada, tornam a promoção estatal da saúde muito distante da afirmação constitucional de que se trata de direito de todos e dever do estado.

O fenômeno da judicialização da proteção ambiental é decorrência da contemporaneidade, verificando-se em diversos ordenamentos. Já no ano de 1998, Cocconi percebia que, em relação ao direito à saúde, corolário da proteção ambiental, verificava-se uma ampliação da intervenção judicial, realizando uma "penetrante opera di controllo sull 'attività della Pubblica Amministrazione suscettibile di influire sulla salubrità ambientale e quindi sull integrità psicofísica dell 'individuo." (tradução livre dos autores: "intensa obra de controle sobre a atividade da administração pública capaz de influir na sanidade ambiental e também na integridade psico-física do indivíduo"). (COCCONI, 1998, p. 76)

Cocconi afirma que, através da construção da categoria dos direitos fundamentais, não passíveis de violação por obra da administração pública, cuja individualização não dependia do poder discricionário, foi possível conduzir a atividade jurisdicional, mesmo diante da repartição da jurisdição. Assim, por essa via, tornou-se natural a atuação jurisdicional em relação ao direito à saúde, já que se "devolve al giudice civile la cognizione delle controversie in cui la Pubblica Amministrazione abbia agito in carenza di potere in concreto" (tradução livre dos autores: "devolve ao juiz civil a cognição das controvérsias nas quais a administração pública tenha agido na falta de poderes concretos"). (COCCONI, 1998, p. 79). 
Essa transferência para o Judiciário, também da função de guardiões da tutela ambiental, também deslocada para o Judiciário, em meio a incessantes discussões conjunturais. Essa nova feição, dada ao Judiciário, exige postura diversa, com a assunção de novos paradigmas. No caso brasileiro, é potencializada pelas dificuldades e deficiências estruturais e conjunturais mas, nem por isso, poderá ser dispensada, dada a importância do bem que está sendo tutelado.

\section{PARTICIPAÇÃO POPULAR E JURISDIÇÃO: UMA NOVA REALIDADE}

O atual papel do Estado brasileiro traçado pela Constituição Federal, em relação à matéria ambiental, é sem dúvida de um Estado imbuído da missão de proteger o direito fundamental ao meio ambiente ecologicamente equilibrado.

Para alcançar esse intento, o Estado deve, por intermédio de seus poderes e órgãos, atuar nas esferas administrativa, civil e penal, a fim de garantir a efetividade e eficácia das medidas protetivas.

O artigo 225, $\S 1^{0}$, da Constituição Federal, contém diversas atribuições ao Poder Público, que objetivam garantir eficácia ao direito enunciado no caput do artigo, dando ênfase, assim, às atitudes de preservação quanto aos possíveis danos que possam ser causados ao meio ambiente. Além das condutas de preservação, não negligencia as providências de ordem repressivas, impondo ao possível degradador o restabelecimento e reparação dos danos que possa vir a causar (SILVA, 2013, p. 862).

A Constituição estabelece, portanto, que o Poder Público tem a obrigação de preservar o meio ambiente, bem de uso comum do povo, devendo utilizar todos os mecanismos de ordem legislativa, 
Participação Popular E Poder Judiciário: Uma Possibilidade...

administrativa e judicial, pois detentor de "[...] um regime jurídico especial que exorbita o Direito Comum" (MORAES, 2011, p. 869). E, para alcançar essa pretensão, é necessário integrar a legislação nacional protetiva com as deliberações internacionais de proteção ao meio ambiente - v.g. tratados, acordos, pactos, entre outros documentos, concretizando-se a proteção do ambiente e evitando danos às presentes e futuras gerações (MORAES, 2011, p. 369-370).

Nesta ordem de ideias é relevante destacar a vinculação que o Poder Judiciário guarda com os direitos fundamentais, no caso o meio ambiente. É intrínseca à própria natureza do Judiciário a função de defender os direitos fundamentais, dando-lhes plena eficácia (MENDES et al., 2010, p. 326).

Além de impor ao Estado a tarefa de proteger e preservar o meio ambiente, o artigo 225 da Constituição Federal impôs igual determinação à coletividade, o que dá um claro caráter de uma democracia-participativa e atuante para os diversos atores sociaiscidadãos, associações, entre outros - (SARLET e FENSTERSEIFER, 2011, p. 229).

A participação da sociedade civil, no modo de produção do Direito em matéria ambiental, pode ocorrer pela iniciativa popular, com a apresentação de projetos de leis, pela indicação de membros da sociedade para comporem órgãos colegiados (como, por exemplo, o CONAMA), pela participação na formulação e efetivação de políticas públicas atinentes a matéria ambiental, pela participação em audiências públicas e plebiscitos e, também, pela atuação na esfera judicial (MILARÉ, 2011, p. 229/231).

Para Bonavides (2003, p. 42/43) a soberania do povo é o marco fundante da democracia participativa, postulado disposto na Constituição Federativa do Brasil, que como tal deve prevalecer.

No entanto, embora a indicação acerca da soberania nacional possa ser encontrada nos escritos de Sieyès, é em Rousseau (1975) que se expressa sua verdadeira feição, claramente disposta no Contrato Social. É nesta obra que se desenha a ideia de um governo 
legitimado pela vontade da maioria - pela vontade do povo. Contudo, mesmo havendo uma divergência em relação os conceitos de soberania em Sieyès e Rousseau, para o último o conceito de povo é o compreendido conforme as ideias daquele, ou seja, povo é a junção de homens numa comunidade.

Deste modo, a doutrina de Rousseau é contrária à necessidade de constituição de partidos, havendo imprescindibilidade da participação popular nas decisões. Assim, cada sujeito é possuidor de uma fração de soberania, ao contrário de Sieyès, onde inexiste essa fragmentação da soberania, porque pertence a toda comunidade (FERREIRA FILHO, 1999, p. 24/25).

Neste ponto é válida a lição de Huszar (1965, p. 13) quando afirma que a sociedade é uma estrutura ativa - com vivacidade -, não um simples agrupamento de pessoas. Considera a sociedade, em verdade, um encadeamento de indivíduos que se relacionam organizadamente.

Canotilho (1998, p. 94) descreve o Estado de Direito Democrático como uma organização de mando apoiada na vontade do povo, onde esta vontade - soberania popular - nada mais é do que "[...] uma das traves mestras do Estado Constitucional. O poder político deriva do "poder dos cidadãos".

E essa soberania popular somente é validada em vista a combinação entre Constituição, Estado e Direito que asseguram uma união harmônica e de confiança no trato entre todos os indivíduos. É necessário ter presente que essas relações devem pautar-se pelos "[...] valores de justiça e liberdade, valores fruídos nas regiões do Estado de Direito e da ordem constitucional da democracia." (BONAVIDES, 2003, p. 344)

O acesso à justiça, portanto, é componente imprescindível para a concretização da participação popular, relevando-se como uma das facetas da democracia participativa insculpida na Constituição Federal. 
Quando trata do tema do direito de ação, como direito de acesso à justiça, Marinoni (2011, p. 191) afirma que esse direito está intimamente ligado à ideia de ordenação do Estado. Diz ser imperiosa a faculdade dos cidadãos de acesso ao Poder Judiciário. Assim, para que se possa assegurar aos indivíduos a participação ativa na sociedade, é necessário o direito de ação, pois "[...] ter direitos e não poder tutelá-los certamente é o mesmo do que não o ter".

Assim, a legitimação dos cidadãos para atuarem judicialmente, individualmente ou por entidades representativas, na busca da efetivação dos direitos sociais ou na implementação de políticas públicas ambientais, sedimenta a disposição de uma democracia direta e participativa da sociedade, interrompendo a noção de uma clássica democracia representativa e mediata (SARLET e FENSTERSEIFER, 2014, p. 145/146).

$\mathrm{O}$ acesso à justiça está disposto no artigo $5^{\circ}, \mathrm{XXXV}$, da Constituição Federal que prevê: "a lei não excluirá da apreciação do Poder Judiciário lesão ou ameaça de direito.” Tal dispositivo assegura o direito de ação, a todas as pessoas, físicas ou jurídicas.

Para Motta (2010, p. 62/63) é pela via processual que o cidadão “[...] não só 'pede jurisdição', mas verdadeiramente dela participa [...]", situação que direciona a efetivação de seus direitos. Sob a ótica da proteção ambiental, estão legitimados os cidadãos a atuarem na via judicial, tornando-os responsáveis pela defesa e preservação do meio ambiente às presentes e futuras gerações caput do artigo 225 da Constituição Federal. É, sem dúvidas, a concretização da possibilidade da democracia participativa.

Na esfera internacional, além da Declaração do Rio sobre Meio Ambiente e Desenvolvimento, mencionada anteriormente, importa citar a Convenção de Aarhus que tem, entre seus propósitos, aquele de assegurar aos cidadãos o acesso à informação, participação do público em processos de decisão e acesso à justiça no tocante às questões ambientais. 
Trata-se de documento arrojado, que dentre outras finalidades, atribui aos órgãos do Poder Judiciário, em todas as suas instâncias, o papel de monitorar a degradação ao meio ambiente perpetrado por particulares ou pelo Poder Público. Da mesma forma, comete ao Judiciário a criação de mecanismos e instruções "adequados e eficazes, bem como justos, equitativos, céleres e não exageradamente dispendiosos, considerando, ainda, a reparação do direito quando necessária [...]" (SARLET e FENSTERSEIFER, 2011, p. 230).

É, portanto, uma Convenção inovadora, que conferiu relevância à função afeta ao Poder Judiciário no trato das questões que envolvem o meio ambiente, afastando a consagrada ideia "de um juiz protagonista" (MOTTA, 2010, p. 63).

Por certo é um documento que destaca o inegável papel do Poder Judiciário, até então considerado um poder onde a função do juiz estaria adstrita a ser uma "mera e passiva inanimada boca da lei" (Cappelletti, 1993, p.32), na atuação incisiva na defesa e proteção do meio ambiente.

E, neste ponto, merece destaque o posicionamento adotado pelo constituinte nacional ao inserir os instrumentos para tutela jurisdicional do ambiente, garantindo aos cidadãos maneiras de atuar em prol do meio ambiente. Para tanto, inseriu no texto constitucional, os seguintes mecanismos: (i) ação direta de inconstitucionalidade de lei ou ato normativo (arts. 102, I $a, 103 \mathrm{e}$ 125, § $2^{\circ}$ ); (ii) ação civil pública (art. 129 , III c/c o $\S 1^{\circ}$ ); (iii) ação popular constitucional (art. $5^{\circ}$, LXXIII); (iv) mandado de segurança coletivo (art. $5^{\mathrm{o}}$, LXX); e (v) mandado de injunção (art. $5^{\mathrm{o}}$, LXXI) (MILARÉ, 2011, p. 231).

Em questões ambientais as ações mais utilizadas são a Ação Civil Pública - Lei no 7.347/85, a Ação Popular - Lei no 4.717/65 e as Ações Direta de Inconstitucionalidade e Declaratória de Constitucionalidade - Lei $\mathrm{n}^{\mathrm{o}}$ 9.868/99, muito embora a regulamentação infraconstitucional dos demais instrumentos: 
Participação Popular E Poder Judiciário: Uma Possibilidade...

Mandado de Segurança Coletivo - Lei $\mathrm{n}^{0}$ 12.016/ o9 e a recente lei sobre o processo e o julgamento dos mandados de injunção individual e coletivo - Lei ${ }^{0} 13 \cdot 300 / 16$.

Estes instrumentos processuais disponibilizados à coletividade fortalecem a legítima e democrática participação popular e barram a "tirania da maioria, sempre latente na fórmula brasileira de presidencialismo de coalização" (Vianna; Carvalho; Melo; Burgos, 1999, p. 51), pautada em proteger os interesses das elites.

A importância destes mecanismos dá a ideia de que uma democracia não é fundada unicamente no ato de eleger representantes, sendo necessário o estímulo aos cidadãos, para uma verdadeira participação voltada aos interesses de todos, especialmente quando se trata da defesa e preservação do meio ambiente. Assim, tem-se que:

A democracia baseada na ação não se estriba nos atos de ouvir, discutir e contar votos; fundamenta-se na participação, no equacionamento dos problemas comuns. A participação criadora dos seres humanos na evolução da sociedade é essencial ao bem-estar geral (HUSZAR, 1965, p. 20).

A autêntica democracia participativa somente estará estruturada quando for afastado o velho Direito Constitucional positivista e formalista, que não se atém à nova realidade apresentada pela Constituição, por via de uma genuína soberania popular, que só produzirá efeitos se for afastada da "ação inclemente e esterilizadora dos legisladores de mandado representativo" (BONAVIDES, 2003, p. 8).

No entanto, para alcançar essa propalada participação popular, é imprescindível a existência e participação de um Poder Judiciário que ceda às amarras de um processo tradicionalmente apegado à dogmática-formalística, devendo o magistrado "[...] assumir postura mais participativa, de modo a relativizar o princípio do impulso oficial [...]" (Sarlet e Fensterseifer, 2014, p. 151) uma vez que o meio ambiente, por se tratar de direito fundamental 
estritamente vinculado à dignidade da pessoa humana, possibilita - e de certo modo até impõe ao juiz - uma atuação em prol de um interesse maior: a proteção do meio ambiente.

O Poder Judiciário - organizado na Constituição Federal entre os artigos 92 a 126 -que tem a função de solucionar conflitos de interesses que são apresentados e que busca garantir "[...] um mínimo de convivência pacífica entre os membros da sociedade" (Antunes, 2014, p. 1222), é hoje um dos principais redutos da tutela ao meio ambiente, sendo o garantidor da democracia participativa.

Por certo que a Constituição Federal - vanguardista e originada da vontade popular - propõe uma resposta ativa do Poder Judiciário, principalmente pelo fato de voltar-se à defesa dos interesses da pessoa humana - Art. $1^{\circ}$, III, da Constituição Federal.

Para que se possa atingir essa condição, é indispensável que aja uma atuação judiciária que realize uma leitura social dos princípios ambientais, concretizando uma verdadeira "[...] Justiça Ambiental, que envolve a democratização de informações ambientais e a participação das minorias sociais na definição de políticas que lhe dizem respeito" (AGUIAR e MAIA, 2014, p. 281).

Na esfera nacional, verifica-se que o Supremo Tribunal Federal tem exercido um papel exemplar nessa esperada atuação - o que, no entender de Cappelletti (1993, p. 74), coloca a Corte Constitucional na condição de um Tribunal "[...] criativo, dinâmico e 'ativista' [...]" - quando iniciou a realização das audiências públicas de relevantes temas sociais, como por exemplo, as audiências relativas aos estudos sobre células-tronco embrionárias, às relativas à judicialização do direito à saúde, dentre outras questões (SARLET e FENSTERSEIFER, 2014, p. 148).

Com esta tomada de direção o Supremo Tribunal Federal dá "[...] um exemplo paradigmático para o nosso Sistema de Justiça, abrindo importantíssimo instrumento de participação pública (e 
Participação Popular E Poder Judiciário: Uma Possibilidade...

também de acesso à informação) na seara judicial" (SARLET e FENSTERSEIFER, 2014, p. 148).

Assim, um agir participativo passa pelos atores sociais, por intermédio dos instrumentos processuais adequados, objetivando assegurar a proteção ambiental que dependerá "[...] necessariamente do Poder Judiciário que, na qualidade de último intérprete da Constituição, deve estar vinculado à eticidade substantiva da comunidade" (CITTADINO, 2000, p. 228).

Tendo presente que a verdadeira democracia encontra-se fundamentada em dois princípios - (i) soberania popular - onde o povo é a origem do poder - e, (ii) participação, direta ou indireta, do povo no poder - legítima expressão da vontade popular (Silva, 2013, p.133), é que o Judiciário apresenta-se como ator ativo, nesta realidade traçada a partir da Constituição Federal de 1988.

Neste novo papel, desenhado para o Poder Judiciário a partir da Constituição, constata-se que ele é o responsável ativo pelas transformações macroestruturais que ocorrem no trato entre o Estado e a sociedade civil. É, também, o instrumento a ser utilizado por esta sociedade para atingir o "[...] território da cidadania ativa e da democracia" (VIANNA et al., 1999, p. 260).

Por certo não se desconhece a crítica mordaz e acerbada, lançada por Bonavides (2003, p. 306-316) em texto escrito no ano de 2003 - "A crise do Judiciário Brasileiro e a nova legitimidade"- sobre um Judiciário, diga-se, o órgão de cúpula, Supremo Tribunal Federal, que se apequena aos mandos de uma política neoliberal destruidora dos valores e princípios constitucionais e aos desmandos de um Executivo que governa por medidas provisórias. Conforme o autor, tem-se uma verdadeira "ditadura constitucional" (p. 311) que se ampliou e lançou-se sobre o Judiciário com as ações declaratórias de constitucionalidade.

Afora, porém, as críticas lançadas há 13 anos, Bonavides (2003, p. 313) aponta para uma democratização do Judiciário, com o reforço e mantença do controle difuso de constitucionalidade, traz a 
esperança do nascimento de uma cidadania "[...] externa as alienações políticas e sociais do sistema representativo. E com ela nascerá também o cidadão da democracia participativa." (BONAVIDES, 2003, p. 314).

Não sem razão, Ovídio Baptista (2004, p. 297-320) ao tecer críticas sobre o capitalismo, ao racionalismo e individualismo dominantes na sociedade crê ser possível

[...] a construção de uma autêntica democracia, quando o individualismo toma o lugar do cidadão. A compatibilidade entre democracia e individualismo é problema crucial que deve ser tratado quando se pretende um direito processual que supere o dogmatismo, porquanto, como sugerimos nas considerações precedentes, o dogmatismo é expressão de um regime autoritário. É, em última análise, a expressão jurisdicional do "pensamento único" neoliberal (2004, p.306)

Dentre as alternativas apresentadas por Ovídio Baptista (2004, p. 319) para uma prestação jurisdicional condizente com a realidade, que podem apaziguar a crise vivida pelo Poder Judiciário, mencionam-se as ações coletivas - ações condizentes com esse novo olhar que se deve ter sobre a democracia participativa. Essas ações ultrapassam os conflitos individuais e desvendam "[...] um campo extraordinariamente significativo para o exercício político da solidariedade, permitindo uma visão comunitária do Direito”.

Para que haja uma participação popular fundada na Constituição passa-se necessariamente por um Judiciário cônscio de seu novo papel na prestação de uma jurisdição que possa efetivar a participação da coletividade, deslocando “[...] o centro das decisões do Direito da consciência do julgador para um lugar mais amplo, mais plural e, consistentemente, mais democrático. Falamos, pois, no processo de uma autêntica jurisdição constitucional.” (MOTTA, 2010, p. 63) 
Participação Popular E Poder Judiciário: Uma Possibilidade...

Deste modo, a concretização deste dever, imposto à coletividade, de defender e preservar o meio ambiente, passa pela noção acerca dessa nova força política que se estrutura - a do cidadão participante e ativo - que, ciente dos seus direitos e deveres interpela um Poder Judiciário inovador e diligente, que tem a responsabilidade de fortalecer essa autêntica democracia participativa, ansiosa por um meio ambiente ecologicamente equilibrado e essencial à sadia qualidade de vida.

\section{CONSIDERAÇÕES FINAIS}

Os problemas ambientais, outrora pensados unicamente na estrutura local, há muito deixaram de satisfazer as expectativas por uma preservação ambiental adequada e condizente com o novo milênio. Deste modo, a máxima ambiental vigente é por pensar mundialmente e agir localmente.

Contudo, esse agir local restringiu-se por muito tempo apenas ao exercício do voto, donde a representação política conduziria à solução de todos os problemas ambientais e garantiria o bem-estar da comunidade.

Mas a tomada de consciência sobre as deficiências deste sistema acabou por se tornar insuficiente, o que contribuiu para que a sociedade lançasse um novo olhar sobre o real papel dos cidadãos numa verdadeira democracia participativa.

Neste contexto, faz-se necessário um novo diálogo entre os atores sociais e os Poderes constituídos, especialmente o Judiciário, buscando formas de implementar o exercício responsável de uma cidadania ativa, que resulte num efetive benefício ao meio ambiente para as presentes e futuras gerações. 
E para alcançar este propósito, é indispensável que a sociedade tenha ciência de todos os instrumentos disponibilizados para sua atuação, na busca de uma defesa e preservação efetiva do meio ambiente, nos moldes do que restou imposto pelo caput do artigo 225 da Constituição Federal.

O direcionamento desta conduta, assim, transita pelo entendimento dos moldes de atuação da sociedade e pela percepção por parte do Poder Judiciário acerca de seu papel para solucionar os anseios perseguidos por este novo grupo político: a do cidadão atuante e efetivamente participativo.

O meio ambiente, que é patrimônio comum, deve ser protegido não só por uma escolha representativa de cidadãos, mas pela atuação direta dos cidadãos por intermédio dos instrumentos processuais colocados à sua disposição.

A força da participação popular há que ser reconhecida, incentivada e especialmente reforçada por um Poder Judiciário atuante e consciente de sua fundamental tarefa no processo decisório, de busca da preservação do meio ambiente e, por conseqüência, da dignidade da pessoa humana.

Data de Submissão: 26/08/2016

Data de Aprovação: 30/10/2017

Processo de Avaliação: double blind peer review

Editor Geral: Jailton Macena de Araújo

Editor de Área: José Ernesto Pimentel Filho

Assistente de Edição: Ilina Cordeiro de Macedo Pontes 
Participação Popular E Poder Judiciário: Uma Possibilidade...

\section{REFERÊNCIAS}

AGUIAR, José de; MAIA, Fernando Joaquim Ferreira. Entre o conservadorismo e o direito das comunidades tradicionais: $\mathrm{o}$ judiciário diante da crítica do movimento por justiça ambiental.

Revista Direito Ambiental e sociedade, v. 4, n. 1, 2014, p. 281. Disponível em:

<http://www.ucs.br/etc/revistas/index.php/direitoambiental/article /view/3693/2116>. Acesso em: 05/07/2016.

ANTUNES, Paulo de Bessa. Direito Ambiental. $16^{\mathrm{a}}$ ed. São Paulo: Atlas, 2014.

AQUILINA, Kevin. IAQUINTA, Pietro (org). Il Sistema Ambiente, tra Etica, Diritto ed Economia. Padova: CEDAM. 2013.

BAPTISTA DA SILVA, Ovídio. Processo e Ideologia: o

Paradigma Racionalista. Rio de Janeiro: Forense, 2004.

BARROSO, Luís Roberto. O controle de Constitucionalidade no Direito Brasileiro. $6^{\mathrm{a}}$ ed. $3^{\mathrm{a}}$ tiragem. São Paulo: Saraiva, 2014.

BOGNETTI, Giovanni. La divisione dei poteri: Saggio di diritto comparatto. Milano: Giuffrè. 1994.

BONAVIDES, Paulo. Teoria Constitucional da Democracia Participativa. $2^{\mathrm{a}}$ ed. São Paulo: Malheiros Editores, 2003.

BRETONE, Mario. Tecniche e Ideologie dei Giuristi Romani. 2. ed. Napoli: Edizioni Scientifiche Italiane. 1982.

BURDEAU, Georges. Traité de Science Politique. Tome III: Le Statut Du Pouvoir dans L`Etat . Paris: Librairie Générale de Droit et de Jurisprudence. 1950.

CANOTILHO, José Joaquim Gomes. Direito Constitucional e Teoria da Constituição. $3^{\text {a }}$ ed. Coimbra: Livraria Almedina, 1998. 
CANOTILHO, José Joaquim Gomes. Constituição da República Portuguesa Anotada. $3^{\text {a }}$ ed. Coimbra Editora, 1993.

CAPPELLETI, Mauro. Juízes Legisladores? Tradução de Carlos Alberto Alvaro de Oliveira. Porto Alegre: Sérgio Antonio Fabris Editor, 1993.

CITTADINO, Gisele. Pluralismo, Direito e Justiça

Distributiva. $2^{\text {a }}$ ed. Rio de Janiero: Lumen Juris, 2000.

CLEVE, Clémerson Merlin. Atividade Legislativa do Poder

Executivo. $2^{\text {a }}$ ed. : São Paulo: Editora Revista dos Tribunais, 2000.

COCCONI, Monica. Il diritto alla tutela della salute. Padova: CEDAM. 1998.

FERREIRA FILHO, Manoel Gonçalves. Aspectos do Direito

Constitucional Contemporâneo. São Paulo: Saraiva, 2003.

FERREIRA FILHO, Manoel Gonçalves. Constituição e Governabilidade: ensaio sobre a (in)governabilidade brasileira. São Paulo: Saraiva, 1995.

FERREIRA FILHO, Manoel Gonçalves. O Poder Constituinte. São Paulo: Saraiva, 1999.

HUSZAR, George B. de. Aplicações Práticas da Democracia. Tradução: J.L. Melo. Rio de Janeiro: Distribuidora Record, 1965.

LOEWENSTEIN, Karl. Political Power and the governmental process. 2. ed. Chicago: The University of Chicago Press. 1965.

MARINONI, Luiz Guilherme. Teoria Geral do Processo. $5^{\mathrm{a}}$ ed. Curso de Processo Civil V.1. São Paulo: Revista dos Tribunais, 2011.

MENDES, Gilmar Ferreira; COELHO, Inocêncio Mártires; BRANCO, Paulo Gustavo Gonet. Curso de Direito Constitucional. $5^{\text {a }}$ ed.: São Paulo: Saraiva, 2010. 
Participação Popular E Poder Judiciário: Uma Possibilidade...

MILARÉ, Édis. Direito do Ambiente: a gestão ambiental em

foco. $7^{\mathrm{a}}$ ed. São Paulo: Revista dos Tribunais, 2011.

MIRANDA, Jorge. Manual de Direito Constitucional. Tomo II. $3^{\text {a }}$ ed. Coimbra Editora, 1996.

MORAES, Alexandre de. Direito Constitucional. 27ª . São Paulo: Editora Atlas, 2011.

MOTTA, Francisco José Borges. Levando o Direito a Sério: uma crítica hermenêutica ao protagonismo judicial. Florianópolis:

Conceito Editorial, 2010.

PROTO PISANI, Andrea. I Diritti e le Tutele. Collana: Trattato di Diritto Civile del Consiglio Nazionale del Notariato. Napoli: Edizione Scientifiche Italiane. 2008.

ROUSSEAU, Jean-Jacques. O contrato social e outros escritos. Tradução Rolando Roque da Silva. 3 a ed. São Paulo: PensamentoCultrix, 1975.

SARLET, Ingo Wolfgang; FENSTERSEIFER, Tiago. Direito Constitucional Ambiental: estudos sobre a Constituição, os Direitos Fundamentais e a Proteção do Ambiente. São Paulo: Revista dos Tribunais, 2011.

SARLET, Ingo Wolfgang; FENSTERSEIFER, Tiago. Princípios de direito ambiental. São Paulo: Saraiva, 2014a.

SIGNORINO, Vincenzo. Valore giuridico della dottrina della separazione dei poteri. Palermo: Libreria della R. Casa. 1908.

SILVA, José Afonso da. Curso de Direito Constitucional Positivo. $37^{\mathrm{a}}$ ed. São Paulo: Malheiros, 2013.

TARUFFO, Michele. Cultura e Processo. Rivista Trimestrale di Diritto Processuale Civile. 2009, 01. Milano: Giuffrè. p. 68-85. 
VIANNA, Luiz Werneck; CARVALHO, Maria Alice Rezende de; MELO, Manuel Palacios Cunha; BURGOS, Marcelo Baumann. A judicialização da política e das relações sociais no Brasil. Rio de Janeiro: Editora Revan, 1999.

WARAT, Luis Alberto. O Monastério dos Sábios: o Sentido Comum Teórico dos Juristas. In: Introdução Geral ao Direito II. Porto Alegre: Fabris, 1996.

ZANON, Nicolò. “La responsabilità dei giudici”. Separazione dei poteri e funzione giurisdizionale. Annuario 2004. Associazione Italiana dei Costitucionalisti. Padova: CEDAM. 2008. 


\title{
Popular Participation And The Judiciary: The Possibility Of Environmental Protection
}

\begin{abstract}
Popular participation, a direct way of achieving popular sovereignty, exists today as a self-structured process inside the socio-environmental state. However, for the materialization of a participatory and effectively active democracy in environmental issues, the society must take conscious action and be duly informed about the available procedural mechanisms. On the other hand, the politicization of the judiciary, which should take a more active role in dealing with environmental matters, is fundamental for the implementation of art. 225 of the Federal Constitution. Thus, this paper discusses the essential relationship between a participatory democracy which aims at defending and preserving the environment and the society's wish for a dynamic and creative judiciary that guarantees the right to an ecologically balanced environment, as an asset of common use by the people and essential to a healthy quality of life. For this research we used the hermeneutic method and the technique used was the bibliographical research, a method that proves adequate to legal science and which allows an understanding of the importance of the effectiveness of environmental procedural protection.
\end{abstract}

Keywords: Participatory democracy. Popular Participation.Access to justice. Judiciary. 